\title{
Pre-Operative IV Iron Infusion for Vascular Patients: Need for More Evidence (Case Series)
}

\author{
Ahmed Nassar and Bryce Renwick* \\ Department of vascular surgery, United Kingdom
}

ISSN: 2578-0379

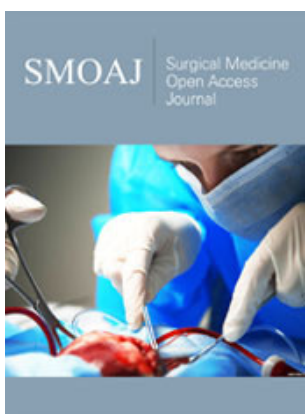

*Corresponding author: Bryce Renwick, Department of vascular surgery, United Kingdom

Submission:

Published: 眥December 02, 2019

Volume 3 - Issue 1

How to cite this article: Ahmed $\mathrm{N}$, Bryce R. Pre-Operative IV Iron Infusion for Vascular Patients: Need for More Evidence (Case Series). Surg Med Open Acc J.3(2). SMOAJ.000557.2019. DOI: 10.31031/SMOAJ.2019.03.000557.

Copyright@ Bryce Renwick, This article is distributed under the terms of the Creative Commons Attribution 4.0 International License, which permits unrestricted use and redistribution provided that the original author and source are credited.

\section{Introduction}

Pre-operative anaemia is present in approximately $30 \%$ of patients undergoing noncardiac surgery [1]. The presence of pre-operative anaemia is the strongest predictor of perioperative blood transfusion and is an independent risk factor for post-operative morbidity and mortality [2]. It is well known that Red Blood Cells (RBC) transfusion can increase the surgical length of stay, increase mortality in surgical patients, and expose patients to the risk of circulatory overload, acute lung injury, and immunosuppression [3-5]. Sufficient data exist to support intravenous iron as efficacious and safe. Intravenous iron should be used as front-line therapy in patients who do not respond to oral iron or are not able to tolerate it, or if surgery is planned for $<6$ weeks after the diagnosis of iron deficiency [6]. The European Medicines Agency concluded that the benefits of i.v. iron exceed the risks when used appropriately (correct indication and dose), without any difference in safety profile among available formulations [7]. We report two vascular cases had peri-operative i.v iron treatment for anaemia.

\section{Case I}

A 71-year-old female patient who was admitted as an emergency for critical limb ischemia of the both lower limbs and presented with rest pain and tissue loss. A Computed Tomography (CT) angiography on admission showed Multilevel disease with severe aortic near occlusive disease, right common iliac and external iliac arteries occlusive disease, severe left common iliac and external iliac stenotic disease and bilateral Common Femoral Artery (CFA) and Superficial Femoral Artery (SFA) and popliteal artery disease (Figure 1). Her past medical history includes ischemic heart disease, previous myocardial infarction, hypertension, osteoarthritis of the spine, partial gastrectomy for gastric ulcer and ex-smoker. The case was discussed in the vascular Multidisciplinary Team (MDT) meeting and the decision made to perform Aorto-bifemoral bypass and bilateral femoral endarterectomy. Her Hemoglobin (Hb) level on admission was $10.3 \mathrm{~g} / \mathrm{dl}$ and ferritin $202 \mu \mathrm{g} / \mathrm{l}$. She had IV iron infusion treatment for 11 days. Repeat $\mathrm{Hb}$ level was $11.2 \mathrm{~g} / \mathrm{dl}$ on the day of the procedure and she did not need intraoperative nor post-operative blood transfusion.

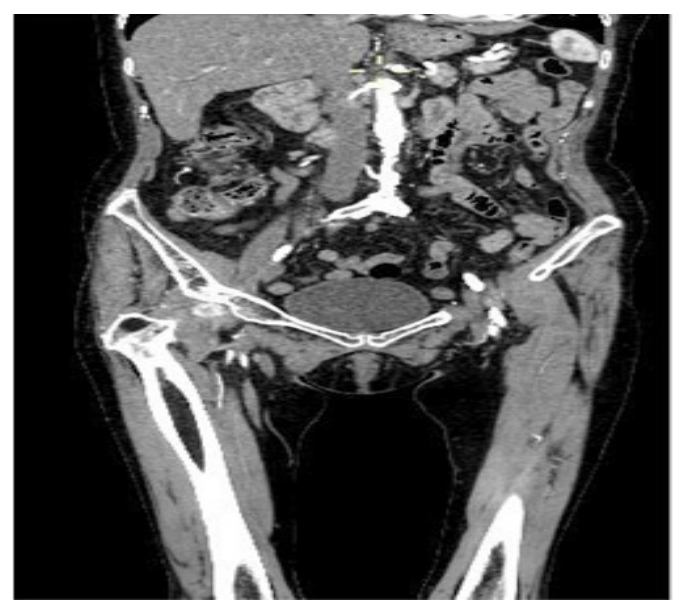

Figure 1: 


\section{Case II}

A 74 year-old female patient who was admitted for Left below knee amputation due to extensive circumferential gaiter's area ulceration, occluded femoropopliteal bypass (Figure 2) and severe pain. Her past medical history includes: Deep vein thrombosis, type 2 Diabetes mellitus, hypertension, pulmonary embolism, Exsmoker and right below knee amputation. She was admitted only one day before surgery when she commenced IV iron infusion. $\mathrm{Hb}$ level on admission was $8.8 \mathrm{~g} / \mathrm{dl}$ and ferritin $101 \mu \mathrm{g} / \mathrm{l}$. She needed only one unit of packed red blood cells on post-operative day 2 because $\mathrm{Hb}$ level dropped to $7.3 \mathrm{~g} / \mathrm{dl}$. After wards, she continued on oral ferrous fumarate $210 \mathrm{mg}$ twice daily and $\mathrm{Hb}$ level was $8.8 \mathrm{~g} / \mathrm{dl}$ 10 days after this.

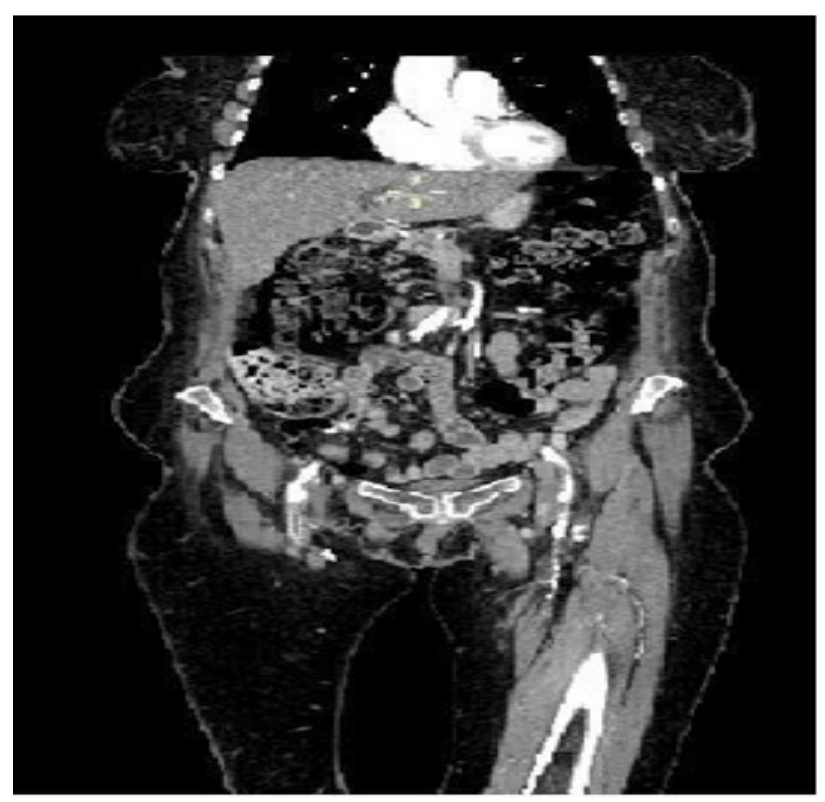

Figure 2:

\section{Discussion}

Several guidelines for the management of peri-operative anaemia have been published over the last decade. However, for anaemia and iron deficiency in adult surgical patients, there are a number of non-evidence based misconceptions regarding prevalence, consequences, diagnosis and treatment, as well as inconsistency of terminology and lack of clear guidance on clinical pathways [6]. Vascular patients are a group of patients with different characteristics. They tend to be of older age group with multiple comorbidities and anaemia of different causes is common. Adding to this, vascular procedures tend to be semi-elective or urgent with not enough time to fully optimize the patient pre-operatively. The above mentioned two cases are a good example for this as both of them had multiple co-morbidities and their procedures were of semi-elective to urgent nature.

In conclusion, we need more studies to investigate pre-operative anaemia management in vascular patients in order to have specific recommendations.

\section{References}

1. Musallam KM, Tamim HM, Richards T (2011) Preoperative anaemia and postoperative outcomes in non-cardiac surgery: A retrospective cohort study. Lancet 378(9800): 1396-1407.

2. Baron DM, Hochrieser H, Posch M, Metnitz B, Rhodes A, et al. (2014) Preoperative anaemia is associated with poor clinical outcome in noncardiac surgery patients. Br J Anaesth 113(3): 416-423.

3. Gross I, Seifert B, Hofmann A, Spahn DR (2015) Patient blood management in cardiac surgery results in fewer transfusions and better outcome. Transfusion 55(5): 1075-1081.

4. Juffermans NP, Prins DJ, Vlaar AP, Nieuwland R, Binnekade JM (2011) Transfusion-related risk of secondary bacterial infections in sepsis patients: A retrospective cohort study. Shock 35(4): 355-359.

5. Vlaar AP, Juffermans NP (2013) Transfusion-related acute lung injury: A clinical review. Lancet 382(9896): 984-994.

6. Munoz M, Acheson AG, Auerbach M, Besser M, Habler O, et al. (2017) International consensus statement on the peri-operative management of anaemia and iron deficiency. Anaesth 72(2): 233-247.

7. European Medicines Agency. New recommendations to manage risk of allergic reactions with intravenous iron-containing medicines. 